\title{
Micromachining of hardened hot-work tool steel: effects of milling strategies
}

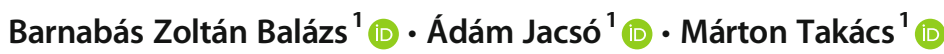

Received: 14 December 2019 / Accepted: 2 June 2020 / Published online: 13 June 2020

(C) The Author(s) 2020

\begin{abstract}
Recently, micro-milling has been one of the most important technologies to produce miniature components, because optional geometrical structures can be machined with a high material removal rate. In terms of conventional dimensions, dynamic milling definitely signals the direction of development in modern technologies: dynamic milling results in higher productivity, better thermal circumstances, and increased tool life. The current paper gives a summary of the possible applications of dynamic milling tool paths in the case of micromachining. The major problems of this technology are the issue of minimum chip thickness and relatively large tool deformation. Different milling strategies, i.e. up milling and down milling, will be compared in detail. A systematic series of experiments were performed in order to generate data for the investigation. A special measuring system was established to perform related data collection. The experiments were carried out on a 5-axis micromachining centre using a tool steel workpiece with a hardness of 50 HRC. Based on the results of the experiments, the force components and the vibrations were also analysed at different radial depths of cut and different feed per tooth values, where productivity was also an important factor. It was found that dynamic milling can be applied in micro sizes, too. It is concluded that in the case of small contact angles, setting as high a feed per tooth value as $23.52 \mu \mathrm{m}$ is also justified. During the investigation, optimal cutting parameters were also determined within the applied parameter range, these are $a_{e}=34.80 \%, f_{z}=8.28 \mu \mathrm{m}$, and the use of the down milling strategy.
\end{abstract}

Keywords Micro-milling $\cdot$ Milling strategies $\cdot$ Dynamic milling $\cdot$ Cutting force $\cdot$ Vibration

\section{Introduction}

During the past few decades, the demand for miniature parts in several industrial areas have increased, which have caused new and significant challenges to modern production technology. To produce micro-components, one of the most efficient technologies is micro-milling: it is capable of producing $3 \mathrm{D}$ surfaces precisely and at relatively high speeds on a wide range of materials with high production flexibility. Currently, the demand for miniature parts is coming mainly from the automotive, airplane, and medical industries [1-3]. With a view to the importance of the selection and application of suitable machining technology, intensive research work has

Barnabás Zoltán Balázs

balazs@manuf.bme.hu

1 Faculty of Mechanical Engineering, Department of Manufacturing Science and Engineering, Budapest University of Technology and Economics, Budapest, Hungary been carried out regarding micro-milling in the past decades. In addition, review papers and summary-purpose books are available, too. However, there are some essential research topics that have not yet produced any relevant results: such is the investigation of different micro-milling strategies [4, 5]. The kinematics of micro-milling and the applied tool geometries are very similar to those applied in conventional size milling. However, due to the size reduction, it is not possible to directly apply parameters used in conventional size cutting, because the micro-milling process has some special characteristics. The technology is characterized by relatively large tool run-out and relatively large tool deformation. In addition, the workpiece anisotropy, grain size, and crystallographic defects also play an important role in the process [6], which is negligible in the case of conventional sizes. Chip thickness to be removed is of similar value as that of the cutting edge radius $\left(r_{\beta}\right)$. Thus, effective cutting angles change significantly [7-9], so cutting occurs with a negative rake angle $[10,11]$. Due to the size effect, the cutting edge radius is significant and, in several researchers' view, minimum chip thickness $\left(h_{\min }\right)$ is the function of the cutting edge radius [11-13]. According to 
the literature, if chip thickness is smaller than $h_{\min }$, ploughing is the main material removal mechanism. In this case, the material undergoes elastic and plastic deformation so classical chip formation resulting from shear will not occur. Due to milling kinematics, chip thickness changes continuously within each rotation of the tool. When chip thickness reaches the value of minimum chip thickness, ploughing effect will decrease, and shearing-based chip forming will commence [10]. Researchers have also investigated the ratio of $h_{\min } / r_{\beta}$ on different materials using different methods including experimental [11-13], numerical [14, 15], and analytical [16, 17]; they have found that the ratio is between 0.2 and 0.4. Aramcharoen and Mativenga [18] found that on hardened, fine grain AISI H13 steel, the size effect is significant if the $h_{\min } / r_{\beta}$ ratio is lower than 1. Mian et al. [19] found that on Inconel 718 material, cutting speed is a significant factor from the perspective of the size effect besides the $f_{z} / r_{\beta}$ ratio. Considering one rotation, in the case of smaller theoretical chip thickness, the cutting edge of the rotating tool starts to remove material only later than the entry of the cutting edge. This means that the ploughing effect has a longer duration. At higher feed per tooth values, ploughing effect decreases because material removal starts earlier. According to Gao et al. [9], the extreme decrease of micromilling feed rate causes an increase of cutting force due to the increased ploughing effect. It was found that high frictional force is the main characteristic of the ploughing mechanism. Biró and Szalay [20] investigated the energetic aspect of the machining process: they examined specific cutting forces in the range of micro chip formation, where a new knickpoint was found. The simulation carried out by Zhou et al. [21] on steeltype NAK 80 shows that the effect of cutting speed on cutting forces is negligible in the investigated parameter range $\left(v_{c}=\right.$ $\left.12-36 \mathrm{~m} / \mathrm{min}, f_{z}=0.3-12 \mu \mathrm{m}\right)$. Wang et al. [22] proved that during the micro-milling of Inconel $718\left(v_{c}=126 \mathrm{~m} / \mathrm{min}, a_{p}=\right.$ $\left.50 \mu \mathrm{m}, a_{e}=100 \mu \mathrm{m}, f_{z}=0.5-4 \mu \mathrm{m}\right)$, cutting force increased concurrently with an increase in feed per tooth and the radial depth of cut. According to the authors, it is advisable to set the feed per tooth value higher than the critical value; concurrently with this, a lower value radial depth of cut should be selected for the purpose of decreasing the cutting force. Sun et al. [23] executed a 3D finite element simulation of Al7075-T6 micromilling, where the dependence of cutting force on the radial depth of cut was analysed.

Kuram and Ozcelik [24] investigated the milling strategies on Ti6Al4V material; the diameter of the applied micromilling tool was $400 \mu \mathrm{m}$. It was found that an increase in rotational speed, from 12,000 to $28,000 \mathrm{rpm}$, can reduce tool wear at a small feed rate $(75 \mathrm{~mm} / \mathrm{min})$ in the case of down milling and zig-zag milling. The aforementioned circumstances affected surface roughness positively; moreover, the ranges of components $F_{y}$ and $F_{x}$ (except in the case of the down milling) decreased. In contrast, at a high feed rate (150 $\mathrm{mm} / \mathrm{min}$ ), an increase in rotational speed increases tool wear in the case of all three strategies. Based on the above study, it can be claimed that when machining at a small feed rate and high rpm, up milling and the zig-zag milling are advantageous, but in the case of a high feed rate and rpm, down milling is the favourable strategy. Oliaeia and Karpat [25] investigated circular pocket milling in micro sizes on a modified AISI 420 steel. According to the authors, small feed per tooth value $(2 \mu \mathrm{m})$ combined with small radial immersion (20\% of tool diameter) resulted in the worst machining conditions. However, smaller radial immersions resulted in better surface roughness than milling using high $a_{e}$ values. An increase in feed per tooth decreases tool wear. In addition, in the case of $60 \%$ radial immersion, tool wear was similar at different $f_{z}$ values. According to Dimov et al. [26], CAM systems should take into account the unique conditions when generating micro-milling tool paths. In light of this, this paper addresses an approach to optimise strategies: the advantages and disadvantages of the different machining strategies are discussed and verified through micro-milling experiments. A well-chosen strategy is essential since it determines surface quality, tool life, and productivity. Moreover, sleek micromilling tools are sensitive to various cutting conditions; but through an appropriate choice of right tool paths, tool failure could be avoided.

As attested by the literature review, there are very few papers (only 3 studies) that deal with an analysis of milling strategies in micro sizes. Furthermore, these studies are only indirectly related to the objectives of the present research. These papers examine different workpiece materials and the application of different ranges of cutting parameters, and they exhibit approaches and objectives different from those of the present study. These studies concentrate on the analysis of surface quality and tool wear, but the forces are only studied to a limited extent. Furthermore, these papers provide no information about vibrations during the micro-milling process. Concerning the optimisation of the process, they merely provide indirect information. Analysed strategies in these papers include tool paths generated by CAM systems and circular pocket milling, but only one paper discusses up milling and down milling processes in more detail. As a part of one of our previous studies, half diameter milling strategies were analysed with respect to the dynamics of micro-milling at different depth of cut values $(25-100 \mu \mathrm{m})$ and different feed per tooth values $(1-12 \mu \mathrm{m})$ on hardened AISI H13. Concerning cutting force, it was found that there are no significant differences between the examined milling strategies. However, according to our findings, the vibrational behaviour of down milling was worse than that of up milling. Moreover, characterising frequencies of micro-milling were also analysed: this showed no significant differences between the different milling strategies [27]. Despite its different objectives and different cutting parameter ranges, this last study provides a good basis for the present research. 
One of the special characteristics of micro-milling is that the material may not necessarily be removed at every rotation in the case of very low theoretical chip thickness values. This is due to the size of the minimum material removal thickness, which depends on the tool edge radius, the properties of the material, and relatively large tool deformation. Uncut layers accumulate and are removed in a single rotation when $h_{\min }$ is reached. This results in relatively large deflection of the tool in the direction of the feed [28-30].

These micro-milling experiments were motivated by conventional size machining, where cutting with small radial depth of cut yields the direction of development in modern cutting technology [31-33]. The following can be mentioned as the advantage of the conventional size machining process: improved productivity and tool life under favourable thermal conditions [34]. Modern milling cycles of CAM systems can generate such tool paths even at complex geometries, and the aforementioned tool paths are able to keep the radial immersion of the tool at a constant value [35]. Related research was aimed at finding that very value of preferred contact angle which offers the possibility to control radial immersion and contact angle [36]. According to the literature, in the case of high-speed machining of difficult-to-cut materials, the high axial depth of cut and small width of cut provide maximum productivity [37]. High axial depth of cut has two main advantages: on the one hand, tool wear is distributed along a larger cutting edge, which results in longer tool life. On the other hand, the effect of the helix angle of the tool is more significant: this provides better dynamical characteristics [34]. Consistent tool load reduces geometrical inaccuracies caused by inconsistent tool deformation [38], and the occurrence of strong vibrations also decreases [39]. In the case of small radial depth of cut, it is possible to increase feed rate in line with the chip thinning phenomenon so that maximum chip thickness can be kept at a favourable value [40]. On the other hand, smaller contact angle means that the tool and the workpiece have smaller surface contact. Thus, the chip can easily be removed along with a major part of the generated heat; therefore, no coolant is required [41]. In fact, this long thin chip allows for longer tool life and better productivity in the case of conventional size milling.

Machining with high depth of cut and small width of cut plays an important role in machining including the production of micro-injection moulding tools. Such kinds of parts often require hardened steels as a base material; however, in the literature, there are relatively few studies which deal with the micromilling of hardened steels. Due to its advantageous propertiesincluding high hot tensile properties, wear resistance, appropriate toughness, and heat checking resistance [42] — hardened AISI H13 was chosen for our experiments. It is a frequently used material for conventional size injection moulding tools; therefore, this material also seems suitable for use in micro sizes. This necessitated its investigation in micro-milling processes.
Based on the literature review, very few papers deal with the investigation of milling strategies in micro sizes. In contrast, there are many papers that examine the influence of "conventional" milling strategies on burr formation. Nevertheless, there are many other important process parameters, such as cutting force components and vibrations, which also have utmost importance with respect to micro-milling.

Based on the above, our research objectives are the following. The main aim of this research is to investigate how material removal occurs in the case of small radial depths of cut. If the contact angle is smaller than $90^{\circ}$, the feed per tooth value is not equal to the theoretical maximum chip thickness, and-in several cases - it does not even reach the minimum chip thickness value. The other main aim of this paper is to investigate whether dynamic milling technology is advantageous in the case of micro-milling, or alternatively — due to the minimum chip thickness problem - different cutting parameters should be chosen. Other objectives include the analysis of the influence of different cutting parameters on cutting forces and vibrations, and the comparison of the applied milling strategies in detail. Moreover, the determination of an optimal cutting parameter combination with high depth of cut and small width of cut in the case of micro-milling is also an objective.

The innovative research presented in this paper provides a large amount of new information. Among others, it gives an idea of the micro-machinability of hardened AISI H13 under dynamic milling conditions and also offers an optimal combination of parameters. The results presented in the scope of this paper can directly be applied in today's industry. Through this, the study also contributes to the economical and wellreproducible production of AISI H13 micro-injection moulding tools and promotes the development of sustainable micromachining.

\section{Experimental conditions}

In the scope of this study, micro-milling experiments were conducted on a VHTC 130 five-axis micromachining centre, which has a maximal spindle speed of $60,000 \mathrm{rpm}$. Force data were obtained with the help of a three-component piezoelectric dynamometer (Kistler 9257A) and a charge amplifier (Kistler 5080A). Vibrations were measured using a onecomponent piezoelectric acceleration sensor (Brüel \& Kjaer 4518-001) with a measuring range of 1-20,000 Hz. The measuring system inside the machine can be seen in Fig. 1. Data collection was performed by two NI USB-4431 sound and vibration devices using LabVIEW software. Data processing and evaluation were carried out with the help of our selfdeveloped software in a LabVIEW environment.

For the experiments, a $500 \mu \mathrm{m}$ diameter, two fluted, AlTiN-coated carbide, micro-end-mill was used. The specifications of the tool are rake angle $(\gamma)$ is $-10^{\circ}$, clearance angle 
Fig. 1 Measurement arrangement inside the machine
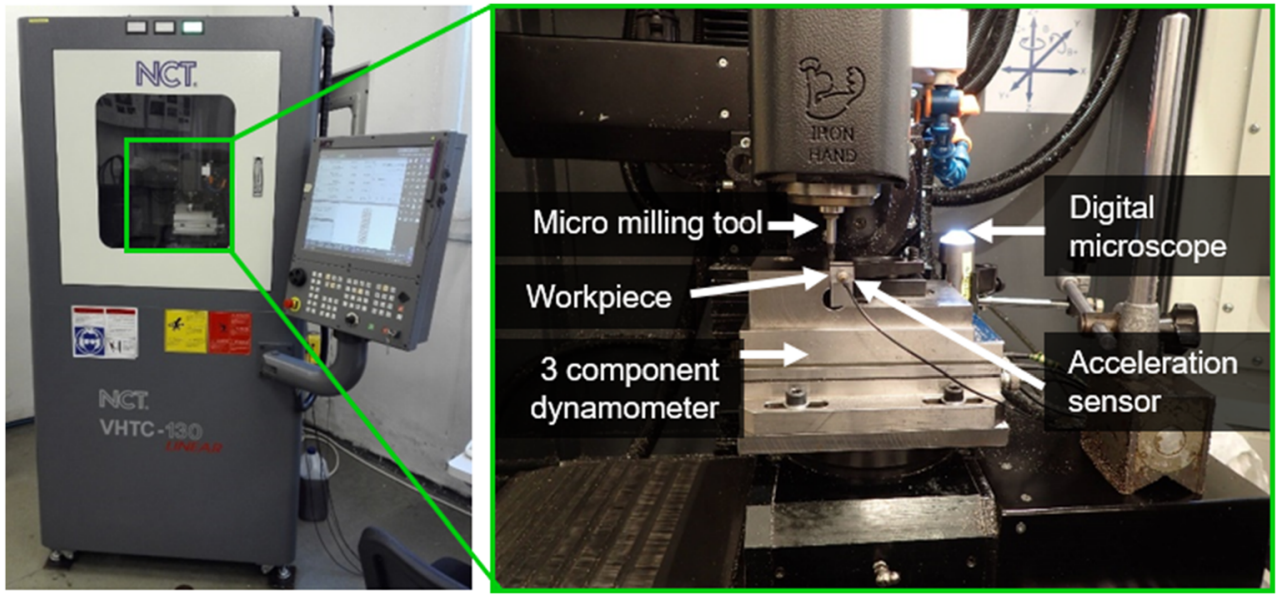

$(\alpha)$ is $13.7^{\circ}$, the helix angle $(\lambda)$ is $25^{\circ}$, and there is a $50 \mu \mathrm{m}$ corner radius that increases the stability of the cutting edge. The cutting edge radius of new tools is $3 \pm 1 \mu \mathrm{m}$. The characteristics of the tool can be seen in Figs. 2 and 4. To minimise the effect of the tool wear on process parameters, a suitably pre-worn tool was used for the experiments. In the rapid initial wear section of the wear curve, tool wear rate is very fast. This is followed by the section of steady-state wear, which accounts for about $80-90 \%$ of the tool life. As a consequence of the break-in period applied, tests were performed in the steady-state wear section. For validation, control measurements were also performed at the beginning and end of the experiments. Based on these, it can be stated that tool wear had no significant effect during the tests. In the experiments, hardened (50 \pm 1 HRC) AISI H13 hot-work tool steel was used.
In the case of macro sizes, dynamical milling is widely used due to its advantages. However, concerning micro-milling, the question arises whether that very material has been removed which is previously set and required. The problem of relatively large tool deformation may cause unstable cutting conditions. Contact angle $(\theta)$ is small at small radial depth of cut, which means that maximum chip thickness is not equal to the set value of the feed per tooth. In this case, the role of $h_{\min }$ is important. In macro dimensions, chip thickness can be calculated as shown in Eq. 1:

$h=f_{z} \cdot \sin \varphi(\mathrm{mm})$

where $\varphi$ is the angular position of the cutting edge.

Another anticipated problem is that a higher force is likely to occur at high depth of cut. As a consequence, tool deformation will probably be greater. As in the case of small feed
Fig. 2 Schematic drawing of the experiments and the applied micro-milling tool

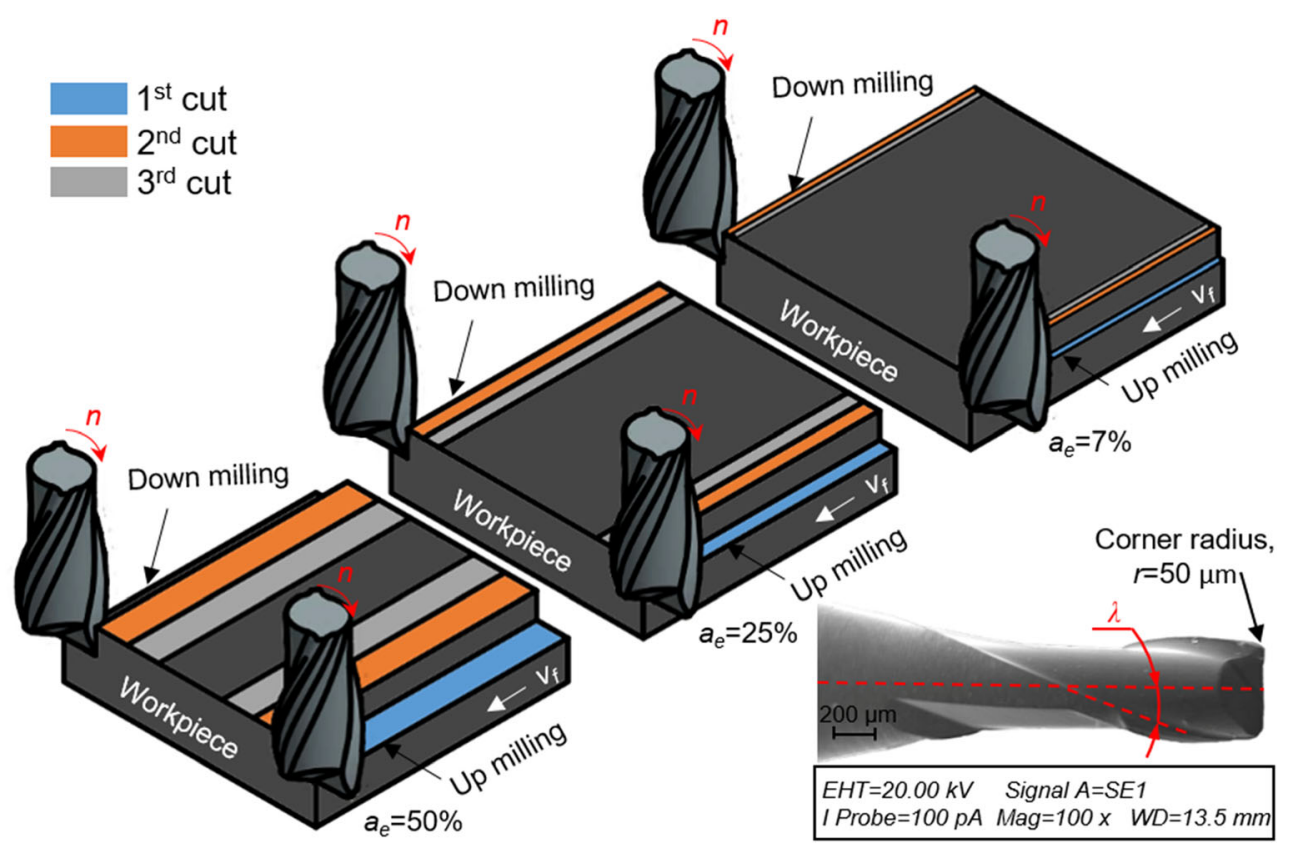


Table 1 Design of experiment

\begin{tabular}{ll}
\hline Cutting parameters & Values \\
\hline$v_{c}(\mathrm{~m} / \mathrm{min})$ & 90 \\
$a_{p}(\mu \mathrm{m})$ & 200 \\
$\theta\left({ }^{\circ}\right)$ & $30,45,60,75,90$ \\
{$\left[a_{e}(\%\right.$ of tool diameter $\left.)\right]$} & {$[7,15,25,37,50]$} \\
$f_{z}(\mu \mathrm{m})$ & $1,4,8,12$ \\
Milling strategy & Down milling, up milling \\
\hline
\end{tabular}

rates, the rotations of the tool without material removal may accumulate $[22,23]$, and in this case-due to large tool deformation - radial cuts may accumulate. Thus, at each setting, cutting was performed three times in consecutive infeeds: in this way, differences among cutting force values (and possibly geometrical inaccuracies) could be observed. The parameters used in the experiments are shown in Table 1. Cutting parameters, factors, and their values were determined based on previous research works by the authors [27, 43], and in line with the recommendations of the tool producers. Moreover, cutting edge radius and the assumed minimum chip thickness value were also taken into consideration. Therefore, as a result of the different setups, chip thickness values encompassed values which are (i) smaller than $h_{\text {min }}$, (ii) correspond to $h_{\min }$, and (iii) are greater than $h_{\min }$. Investigated parameter ranges were chosen so that they are interpretable and valuable for the modern industry. The schematic drawing of the micro-milling experiments is shown in Fig. 2. In the figure, the places of consecutive infeeds are displayed as $1^{\text {st }}$ cut, $2^{\text {nd }}$ cut, and $3^{\text {rd }}$ cut, respectively.

During the experiments, cutting speed was $v_{c}=90 \mathrm{~m} / \mathrm{min}$, which is close to the maximum rpm of the main spindle, and the depth of cut was $a_{p}=200 \mu \mathrm{m}$. Radial depths of cut were determined based on the contact angles $(\theta$, shown in Table 1). The $a_{e}$ values belonging to $\theta$ are given as a percentage of the tool diameter in Table 1: the values are 7, 15, 25, 37, and 50\%, respectively. During the experiments, all possible cutting parameter combinations were set. Chip thickness markedly decreases at small contact angles. For this reason, at $\theta=30^{\circ}$, two more $f_{z}$ values $(15.68,23.52 \mu \mathrm{m}$ feed per tooth) and, at $\theta=$ $45^{\circ}$, one more $f_{z}$ value $\left(f_{z}=16.8 \mu \mathrm{m}\right)$ were added to the settings. Thus maximum chip thickness was comparable with the values at high contact angle.

Figure 3 shows how chip thickness changes due to the kinematics of milling in the case of up milling. The yellow colour designates the region where the dominant material deformation mechanism is ploughing, and the green colour shows the region where chip formation due to conventional shearing mechanism occurs. In the figure, the path of three consecutive edge impacts can be seen. The figure also shows the influence of the contact angle on chip thickness.

Similarly to Fig. 3, Fig. 4 shows chip thickness variation from the point of view of orthogonal cutting. The constructive geometry of the micro-milling tool can be seen in Fig. 4. It is also clear that effective cutting angles are significantly influenced by actual chip thickness during an edge impact due to the size effect. As a consequence, effective cutting angles varied from point to point during every edge impact. Just like Fig. 3, Fig. 4 uses the same colours: the figure shows three scenarios at different $h$ values: (i) the actual rake angle is $-10^{\circ}$ when chip thickness is significantly greater than the $h_{\min }$ value; (ii) $\gamma_{\text {eff,1 }}$ shows the actual rake angle when $h \approx h_{\text {min }}$; in this case, the value of $\gamma$ is much smaller than in the case of (i); (iii) $h<<h_{\text {min }}$ results in an extreme negative rake angle $\left(\gamma_{\mathrm{eff}, 2}\right)$, which contributes to a strong ploughing effect. Moreover, the feed per tooth value also has an effect on chip thickness, and it basically determines the ratio of the ploughing-dominant region to the shearing-dominant region.

\section{Results}

\subsection{Cutting forces}

Information about cutting forces is important for understanding the micro-milling process in depth. The knowledge of such information allows for a more precise understanding of material separation. Furthermore, cutting force is also related to material removal mechanisms, the volume of removed material, and the nature of chip formation. In the case of micro-

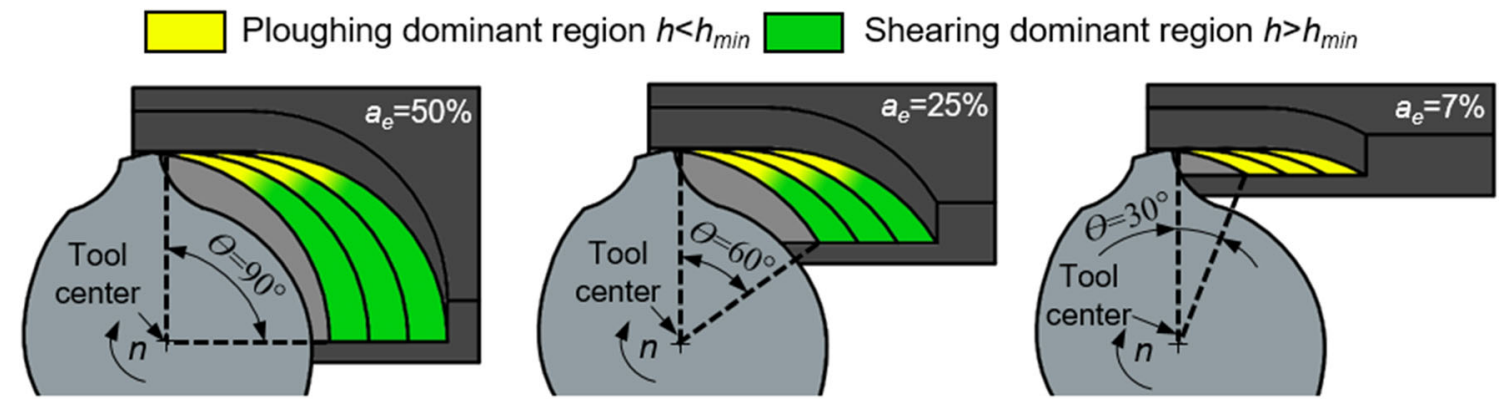

Fig. 3 Chip thickness variation at the impacts of the cutting edges and the effect of contact angle 
Fig. 4 Micro chip removal process and the influence of uncut chip thickness

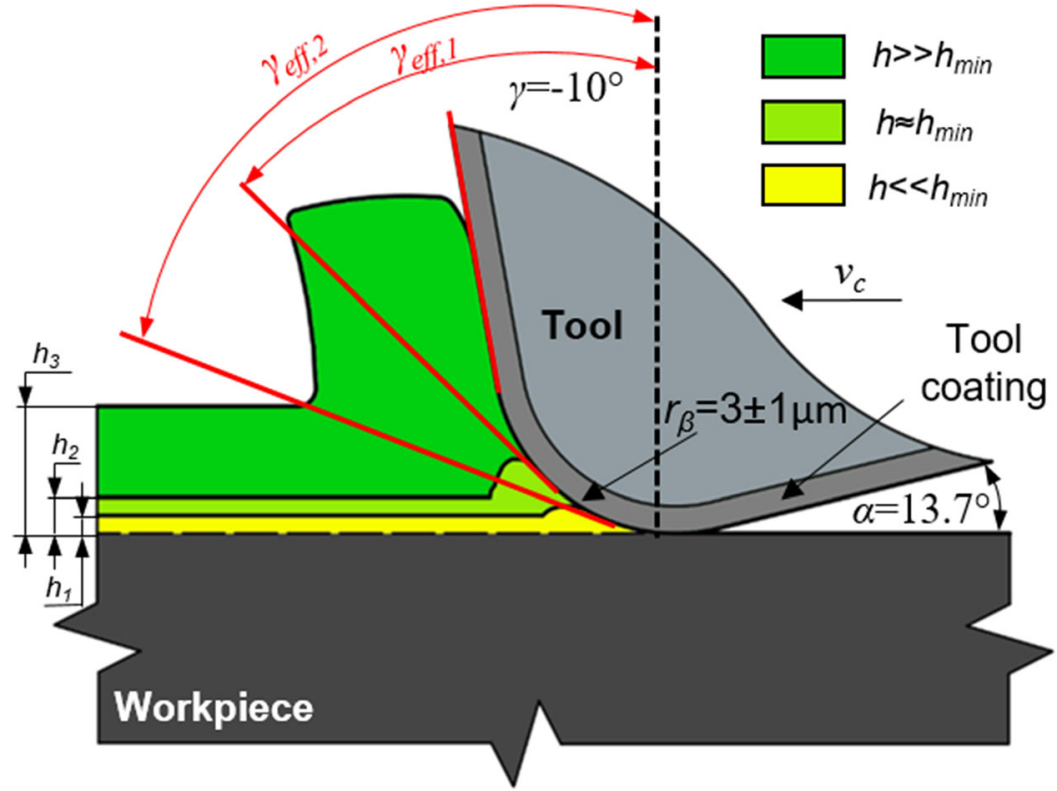

milling, cutting force is also responsible for tool deformation, which may cause backward scratching of the tool. And as force data directly provide information on tool conditions, changes in force data are in connection with tool wear. A thorough analysis of cutting force provides a basis for process monitoring. An application developed in LabVIEW was used to evaluate forces. At each setup, maximum force values were collected from 100 consecutive rotations, and the average of these was considered as the basis of analysis. The results are shown in Figs. 5, 6, 7, 8, and 9.

At small contact angles, a clear trend was observed in the case of up milling: cutting force increased by consecutive infeeds. For example, in the case of $a_{e}=7 \%$ and at $f_{z}=12$ $\mu \mathrm{m}$, cutting force at the first cut was $2.99 \mathrm{~N}$ and at the third cut, it was $6.8 \mathrm{~N}$, so the force doubled in the same setting. Control experiments were performed (at $f_{z}=8$ and $12 \mu \mathrm{m}$ ) in order to further investigate this phenomenon: the experiments did not reveal a significant difference. The reason for an increase in forces could be the problem of minimum chip thickness. At small radial depths of cut, the same cutting force can cause more considerable tool deformation due to unremoved material layers and the absence of axial support. However, in this case, small tool deformation can cause relatively large differences in the material layer removed and thus also in cutting force. All of these result in unstable cutting circumstances. The results belonging to $7 \%$ radial depth of cut are shown in Fig. 5a. The observed tendencies are similar at $a_{e}=15 \%$ too, but a further increase in the radial depth of cut will not yield significant differences.

In general, in the case of up milling, cutting forces increase concurrently with an increase in the feed per tooth value. This was expected due to the increase in chip crosssection. However, it was also observed that changes in cutting force at consecutive infeeds were influenced by the radial depth of cut. Cutting forces increased when $a_{e}$ $=7 \%, a_{e}=15 \%$, and $a_{e}=25 \%$ were applied (Figs. 5, 6, and 7 ). In contrast, when the radial depth of cut was $37 \%$, the values were almost the same at consecutive infeeds (Fig.
Fig. 5 Cutting force tendency at $a_{e}=7 \%$ based on feed per tooth in the case of $\mathbf{a}$ up milling and $\mathbf{b}$ down milling
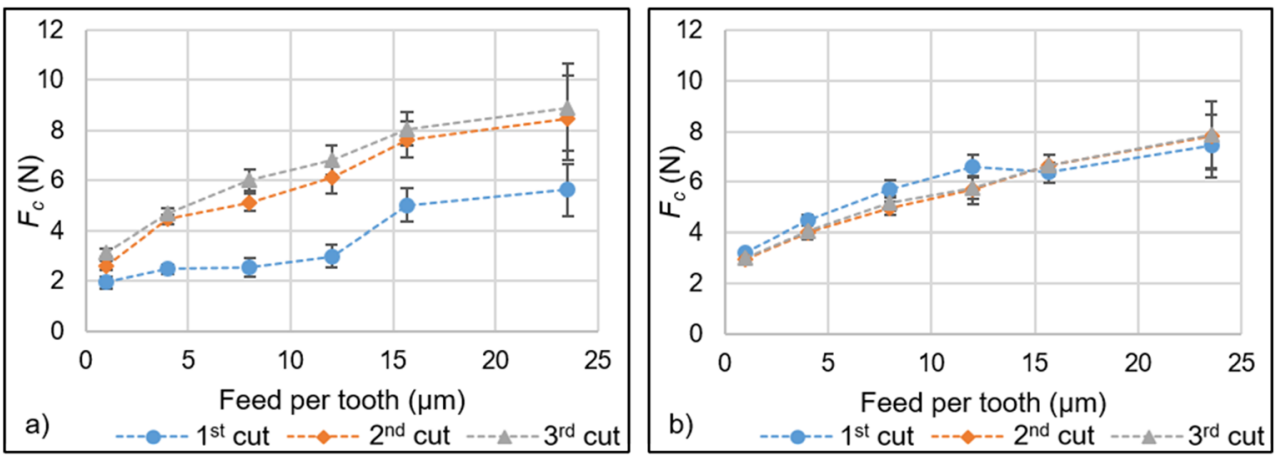

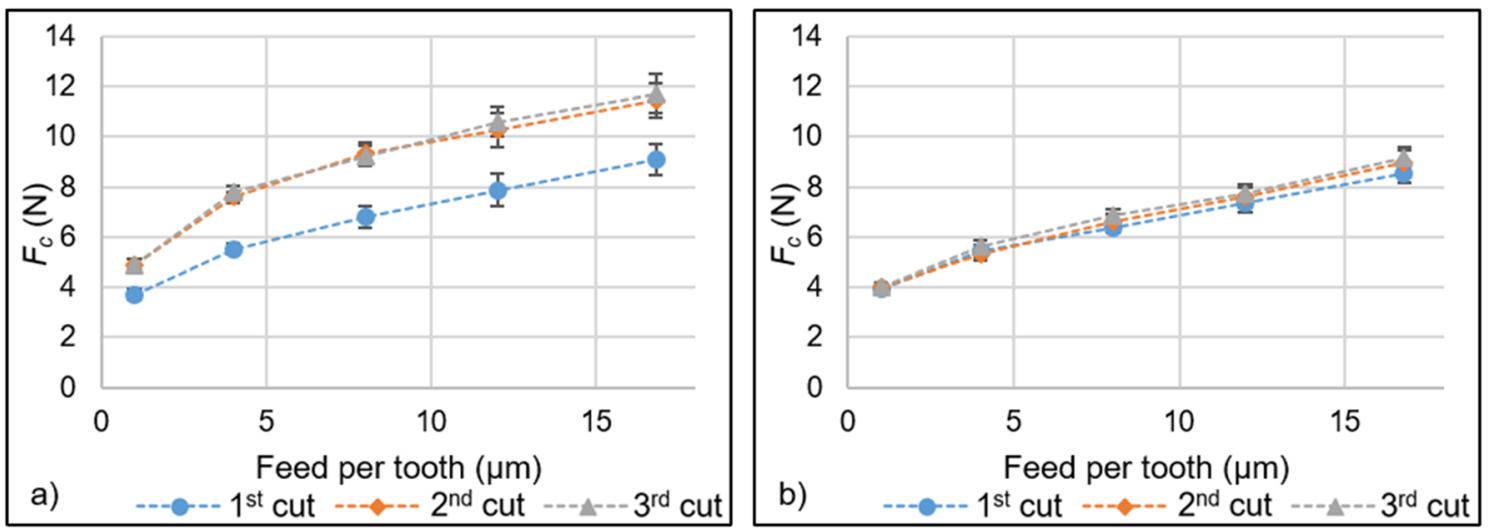

Fig. 6 The influence of feed per tooth on cutting forces when $a_{e}=15 \%$ in the case of $\mathbf{a}$ up milling and $\mathbf{b}$ down milling

8 ), but a further increase of $a_{e}$ to $50 \%$ resulted in an increase yet again (Fig. 9).

It was likewise observed that in the case of down milling, forces decrease at consecutive infeeds when $a_{e}=7 \%$. However, the difference in values at consecutive infeeds is significantly smaller than in the case of up milling. Figure 5 clearly shows that an increase in feed per tooth value $\left(f_{z}=\right.$ 15.68 and $23.56 \mu \mathrm{m}$ ) yields even more consistent results. At this point, it can probably be claimed that a favourable $h$ value (from the point of view of chip removal) has been achieved: here actual material removal occurs at every single edge impact due to the kinematics of the milling process and the applied feed per tooth value. In contrast with the up milling strategy, in the case of the down milling strategy, there appears no difference in the case of consecutive infeeds from a value of $a_{e}=15 \%$ upwards: here the results are uniform (see Fig. $8 b)$.

Upon comparing the two strategies, we can state that in the case of down milling, forces were smaller in most of the cases, the only exceptions were the values of $f_{z}=1$ and $4 \mu \mathrm{m}$ in combination with the values of $a_{e}=7 \%$ and $a_{e}=15 \%$. When quantifying differences, we can observe the following data: when $a_{e}=25 \%$ and $f_{z}=12 \mu \mathrm{m}$ were applied, the values were between 11.13 and $11.62 \mathrm{~N}$ in the case of up milling using 3 consecutive infeeds, while in the case of down milling, the values were between 8.09 and $8.7 \mathrm{~N}$. In contrast, in the case of 50\% radial depth of cut, the results were approximately the same with respect to both strategies.

Figure $8 \mathrm{~b}$ shows that when $a_{e}=37 \%$, the increase of force was minimum between the range of $f_{z}=4$ and $f_{z}=8 \mu \mathrm{m}$, but in the case of other settings, clear trends were observed.

In the scope of this study, analysis of variance (ANOVA) was also used for the evaluation of experimental data. The results of ANOVA are shown in Fig. 10 and Table 2. For the analysis, cutting parameters in Table 1 were applied, but further settings with increased $f_{z}$ values were disregarded. The $F_{\text {crit }}$ value for the $F$ test was 3.925 at a significance level of $\alpha=0.05$.

As attested by the results of the ANOVA, the effects of the three examined cutting parameters and consecutive infeeds are also statistically significant. In fact, the radial depth of cut has the largest effect, which is followed by feed per tooth and milling strategy, with the effect of consecutive infeeds falling last. The factors (arranged in a list of decreasing effect), their main effects, and the related $F$ values and $P$ values are listed in Table 2.
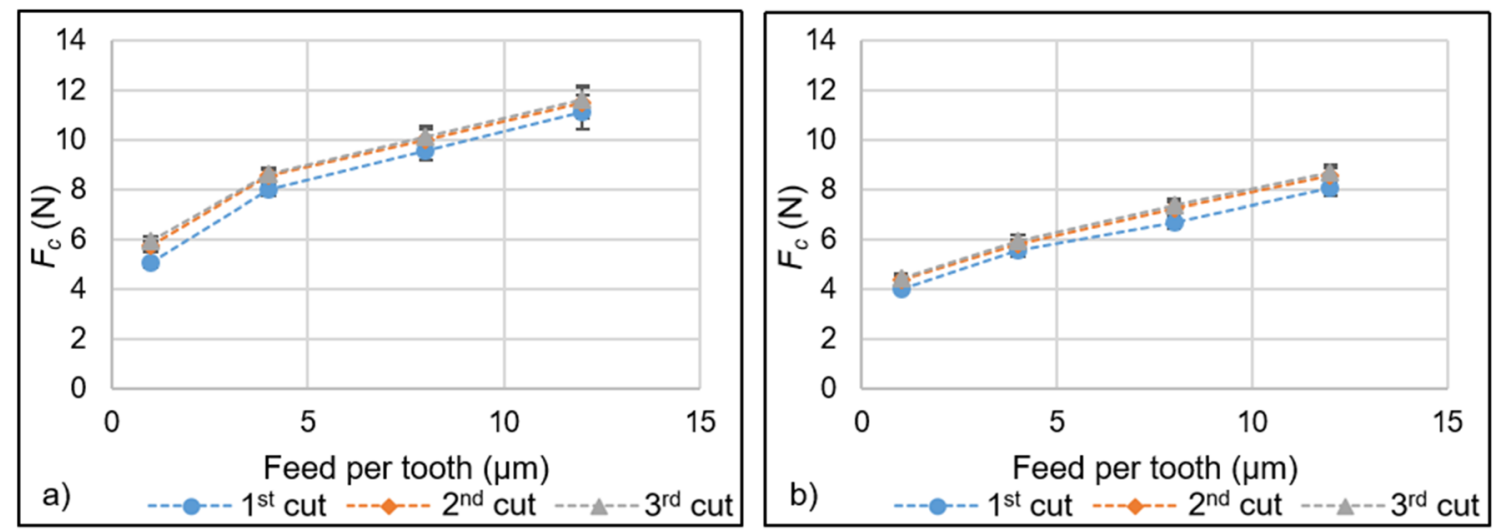

Fig. 7 The influence of feed per tooth on cutting forces when $a_{e}=25 \%$ in the case of $\mathbf{a}$ up milling and $\mathbf{b}$ down milling 

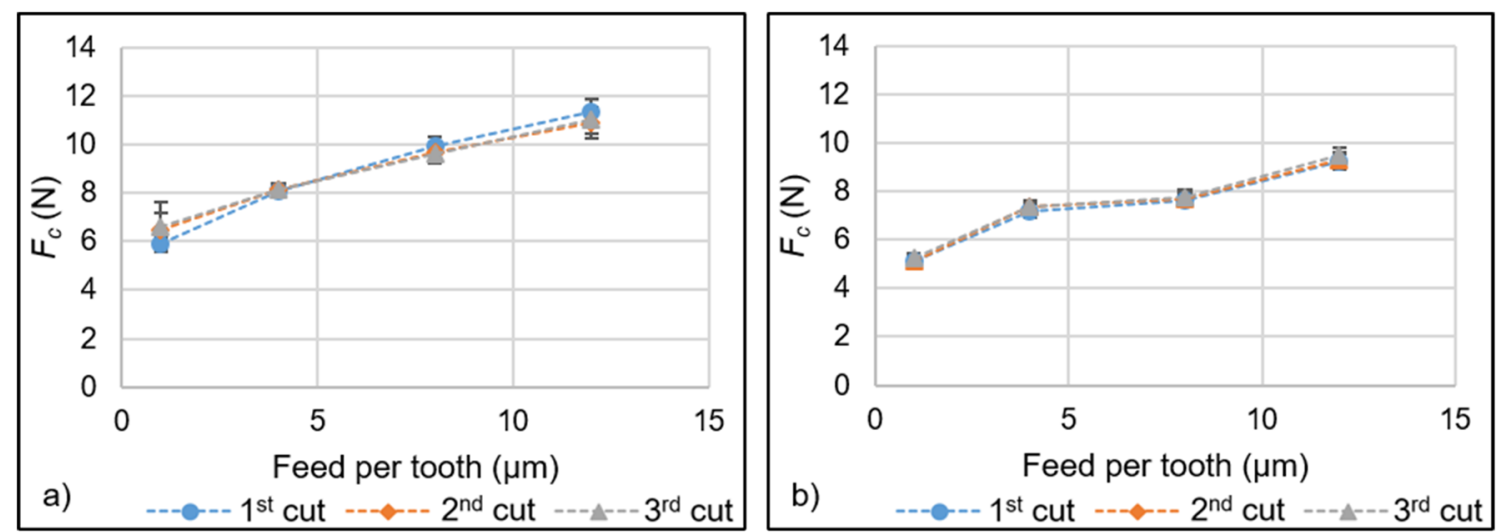

Fig. 8 Cutting forces at different feed per tooth values when $a_{e}=37 \%$ in the case of a up milling and $\mathbf{b}$ down milling
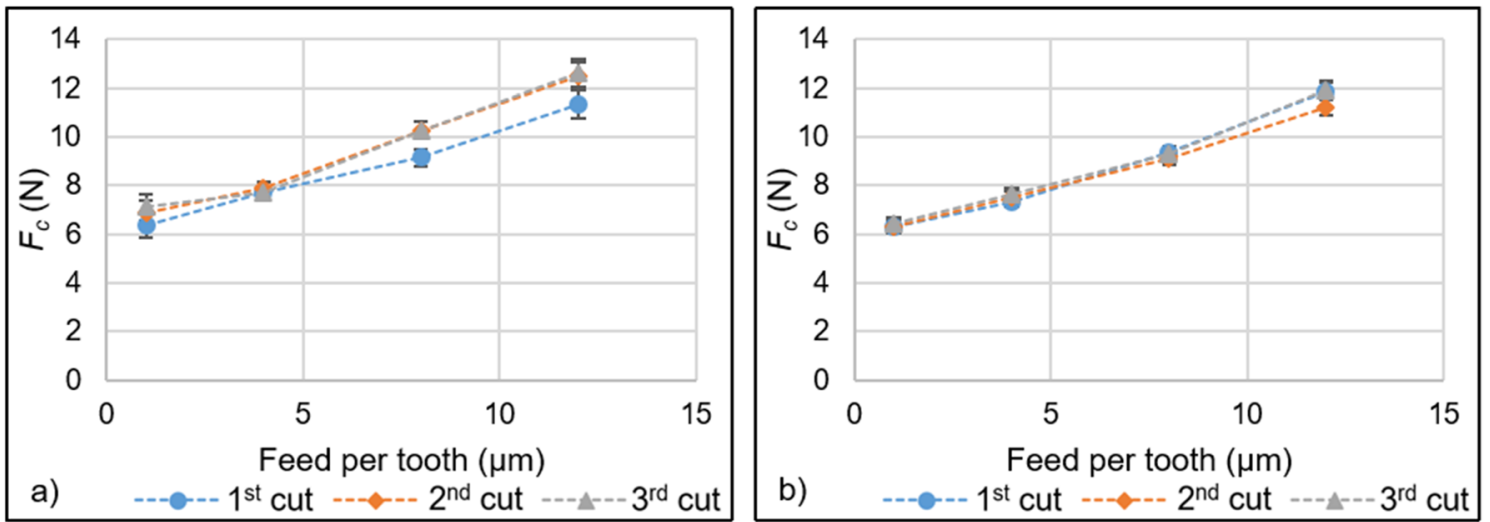

Fig. 9 Cutting forces at different feed per tooth values when $a_{e}=50 \%$ in the case of $\mathbf{a}$ up milling and $\mathbf{b}$ down milling

Based on the analysis of the interaction between the parameters, it can be stated that solely the interaction between $f_{z}$ and $a_{e}$ has a statistically significant effect $(F$ value $=7.21, P$ value $=0.008)$. In the case of further interactions, the null hypothesis cannot be rejected.

\subsection{Axial forces}

Familiarity with axial force components is important in many respects. This force component has an effect on the geometric inaccuracies of structure depth and on the elastic spring-back of the material. Due to the complexity of the cutting process, a detailed analysis of forces is important, since the forces and their changes are related to numerous phenomena.

Axial force components at consecutive infeeds show few differences, the only exception is $a_{e}=7 \%$ in the case of up milling (Fig. 11a). Similarly to $F_{c}$, axial forces are smaller in the case of the down milling strategy (Fig. 11).

The difference between the milling strategies was the smallest in the case of $a_{e}=50 \%$ (up milling $3.74-5.14 \mathrm{~N}$ vs. down milling 3.07-4.00 N) in contrast to $a_{e}=7 \%$, where the values were in the range of $1.92-7.29 \mathrm{~N}$ and $1.31-3.04 \mathrm{~N}$, respectively. In the case of both strategies, the smallest axial forces were observed at $a_{e}=25 \%$. Figure 11 shows force values in the case of $a_{e}=7 \%$ : here, a clear tendency of increase can be seen. It was also observed that when extreme feed per tooth values $(15.68$ and $23.52 \mu \mathrm{m})$ were set, the change of forces was very small in the case of up milling.

However, not all settings show a clear trend (Fig. 12). In Fig. $12 \mathrm{~b}$, a local minimum point can be seen. Taking into

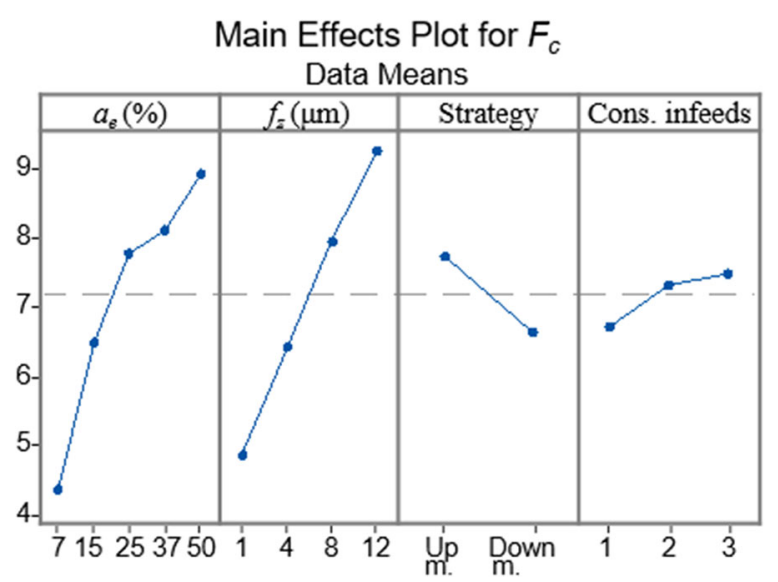

Fig. 10 Main effects plot for cutting force 
Table 2 ANOVA results

\begin{tabular}{llrl}
\hline Factors & Main effect & $F$ value & $P$ value \\
\hline$a_{e}$ & $4.57 \mathrm{~N}$ & 250.92 & 0.000 \\
$f_{z}$ & $4.41 \mathrm{~N}$ & 323.83 & 0.000 \\
Milling strategy & $1.10 \mathrm{~N}$ & 39.72 & 0.000 \\
Consecutive infeeds & $0.77 \mathrm{~N}$ & 11.00 & 0.001 \\
\hline
\end{tabular}

account tool load, the local minimum point defines an optimal parameter range at the given cutting conditions. Due to the kinematics of up milling, the cutting edge enters the material with zero chip thickness. At this point, and until the $h_{\min }$ value has been reached, there is no distinct chip forming because in this case, the main material deformation mechanism is ploughing (Figs. 3 and 4). This means that the material is deformed plastically and elastically [10]. Due to unfavourable cutting conditions and unremoved material layers, tool deformation can be larger. This deformation causes a small tilting of the axis of the tool at the end of the flutes. Since cutting force impacts on the perpendicular plane of the tool axis, in this scenario, $F_{c}$ also has a component in the axial direction, which may play a role in the increase of $F_{z}$.

If removed, maximal chip thickness is taken into consideration, measured forces are almost the same in the case of the following parameter combinations: $a_{e}=15 \%-f_{z}=4$ and $a_{e}=$ $50 \%-f_{z}=1 \mu \mathrm{m}$. However, in other cases, significant differences can be seen in forces. Thus, force values are different in the case of different cutting parameter combinations with a given chip cross-section. In order to determine an optimal parameter combination, the investigation of these differences is important, which is also discussed in this paper.

In the case of the axial force component, the analysis of variance shows that the examined cutting parameters have a significant effect on output parameters. In contrast to the result of $F_{c}$, the same null hypothesis at consecutive infeeds cannot be rejected. The main effect plots and related results are shown in Fig. 13 and Table 3. Milling strategy has the greatest effect followed by radial depth of cut and the feed per tooth value.

In the case of this force component, interactions are considerable. The interactions between $a_{e}$ and $f_{z}(F$ value $=6.91, P$ value $=0.010), a_{e}$ and milling strategy $(F$ value $=24.67, P$ value $=0.000), a_{e}$ and consecutive infeeds $(F$ value $=5.94, P$ value $=0.016), f_{z}$ and milling strategy $(F$ value $=22.21, P$ value $=0.000)$, as well as - from among the three-way interactions - the effect of $a_{e}, f_{z}$, and milling strategy ( $F$ value $=5.16, P$ value $=0.025$ ) have a statistically significant effect. The results can be seen in the interaction plots shown in Fig 14.

\subsection{Vibrations}

Vibrations impact tool life, burr formation, and surface quality. Vibrations are also related to the current state of tool wear; therefore, information about vibration is important for the cutting process and for process monitoring applications. Vibrations are caused by the intermittent nature of the milling process, relatively large tool deformation, relatively large tool run-out, the anisotropic properties of the material, and the problem of minimum chip thickness. In order to determine the reasons of vibrations, and to reduce vibrations indirectly, it is necessary to know the nature of such vibrations. Furthermore, vibrations provide important information about the material removal process. In the case of chip thickness below the value of $h_{\text {min }}$, vibrations may be larger due to unstable cutting conditions. Consecutive infeeds may also generate increased vibrations due to the impact of the traces originating from the previous cut. This phenomenon is similar to the regenerative effect.

In the scope of the present research, results were measured by a one-component piezoelectric acceleration sensor, which can be seen in Figs. 15, 16, and 17 with reference to different width of cuts. At $a_{e}=7 \%$ radial depth of cut (Fig. 15), vibration amplitudes were higher during down milling (up milling 10.51-23.15 m/s $\mathrm{s}^{2}$, down milling
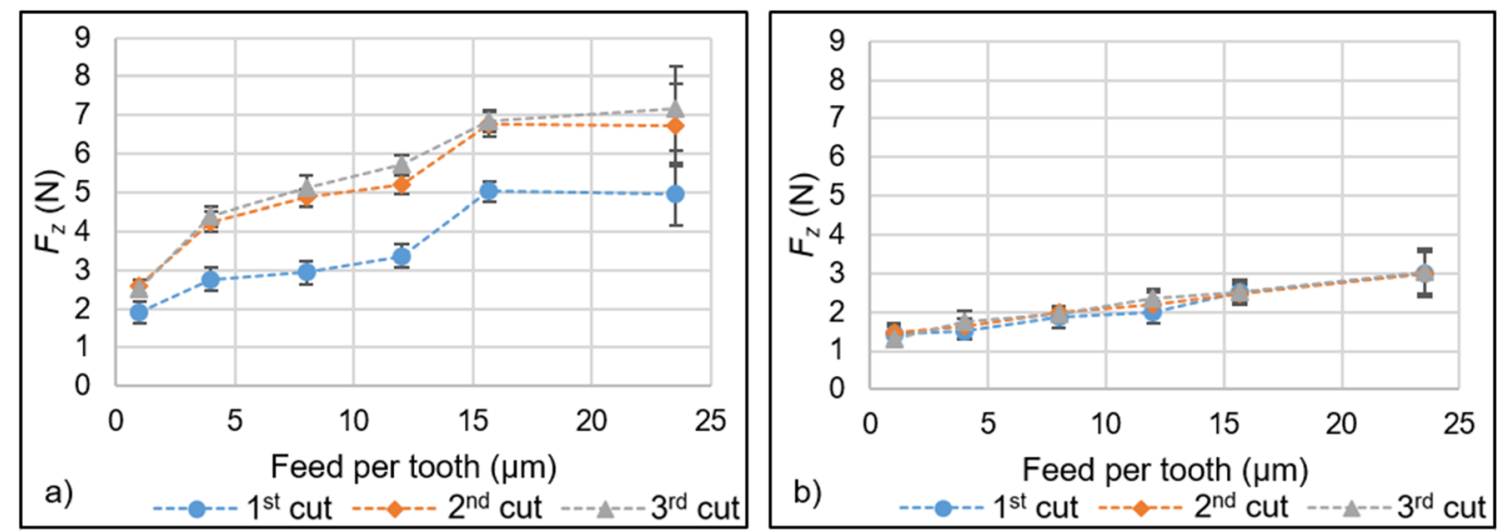

Fig. 11 Force component $F_{z}$ when $a_{e}=7 \%$ at different feed per tooth values in the case of a up milling and $\mathbf{b}$ down milling 

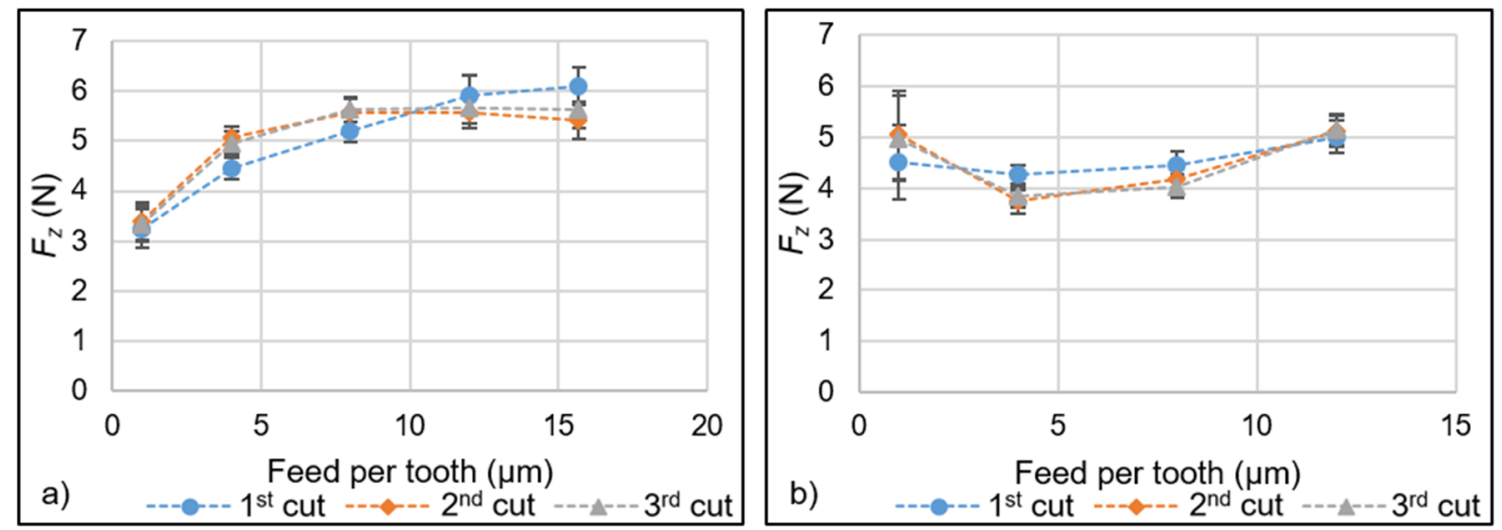

Fig. 12 Force component $F_{z}$ in the case of up milling as a function of feed per tooth values when $\mathbf{a} a_{e}=15 \%$ and $\mathbf{b} a_{e}=50 \%$

$29.17-40.70 \mathrm{~m} / \mathrm{s}^{2}$ ). Due to the kinematics of the down milling process, the cutting edge enters the material with maximum chip thickness. This can generate higher vibration amplitudes than those impacting in the case of up milling. During up milling, the edge impact starts with zero chip thickness, and theoretically, the $h$ value and the forces increase continuously until the flute exits the material. Moreover, in the case of this small $a_{e}$ value (especially when feed per tooth values are smaller), it is assumed that there is no actual material removal in every single edge impact. All of these can explain the significant differences shown in Fig. 15.

The results of machining with consecutive infeeds do not show significant differences with respect to any of the strategies. The only exception is $f_{z}=1 \mu \mathrm{m}$ up milling. It is a wellknown phenomenon that cutting edges leave vibration traces on the machined surface. The reason for a huge increase may be that the previous traces generate much more vibration during the second and third infeeds. All of these contribute to the onset of regenerative chatter, which can result in a tendency of increased vibration. In this case, control experiments were carried out, where vibration amplitudes varied within a small

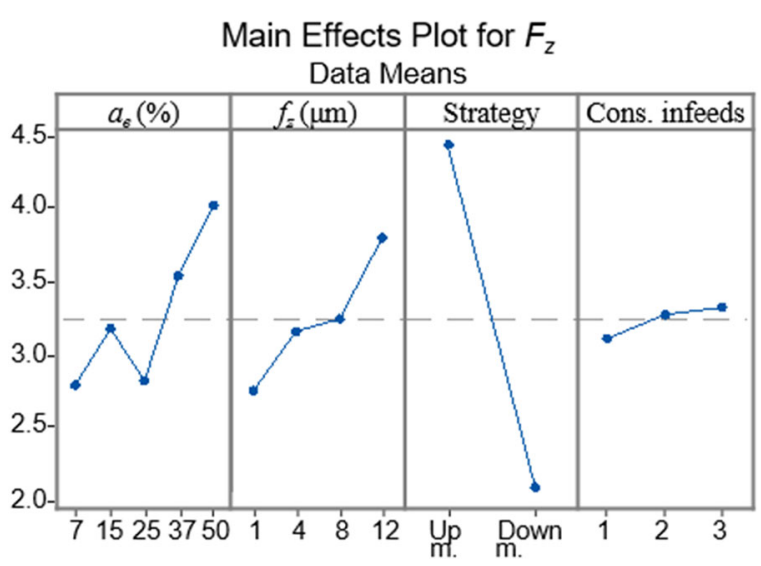

Fig. 13 Main effects plot for axial forces range, and referent average values were between 13.51 and $15.78 \mathrm{~m} / \mathrm{s}^{2}$. However, in this scenario, force values were significantly higher. This setting results in very small chip thickness, which is significantly smaller than the $h_{\text {min }}$ value; therefore, it is assumed that there is no actual chip removal during each edge impact. Due to the given unstable conditions and inconsistent values, it is proposed that this parameter setting should be avoided.

During up milling, this tendency shows a slight decrease. Even if the two extreme feed rates increase vibrations, these values still remain low. In contrast, a decrease in vibrations was found when values were greater than $4 \mu \mathrm{m}$ feed per tooth in the case of down milling, and this scenario persisted even in the case of the two extreme feed rates. This means that cutting conditions improved, mainly due to an increase in chip thickness. At times when the $a_{e}$ value increased, stagnation in vibration was observed when $a_{e}=15 \%$.

When $a_{e}=25 \%$ (Fig. 16), there is an increasing trend in the case of both strategies. Nevertheless, if all three consecutive infeeds are taken into account, differences between the strategies are no longer significant. Referent values varied between 16.42 and $54.06 \mathrm{~m} / \mathrm{s}^{2}$ in the case of up milling and between 12.55 and $49.27 \mathrm{~m} / \mathrm{s}^{2}$ in the case of down milling, but vibration amplitudes were high only during the first cut when down milling was used (Fig. 16b). The reason for the decrease in vibrations at the second and the third infeeds is that the contact zone between the cutting edges of the tool face and the workpiece is larger due to the previously machined geometry. On

Table 3 Results of ANOVA in the case of $F_{z}$ forces

\begin{tabular}{llrl}
\hline Factors & Main effect & $F$ value & $P$ value \\
\hline Milling strategy & $2.35 \mathrm{~N}$ & 630.02 & 0.000 \\
$a_{e}$ & $1.23 \mathrm{~N}$ & 73.55 & 0.000 \\
$f_{z}$ & $1.04 \mathrm{~N}$ & 56.29 & 0.000 \\
Consecutive infeeds & $0.21 \mathrm{~N}$ & 2.69 & 0.104 \\
\hline
\end{tabular}


Fig. 14 Interaction plots for axial forces

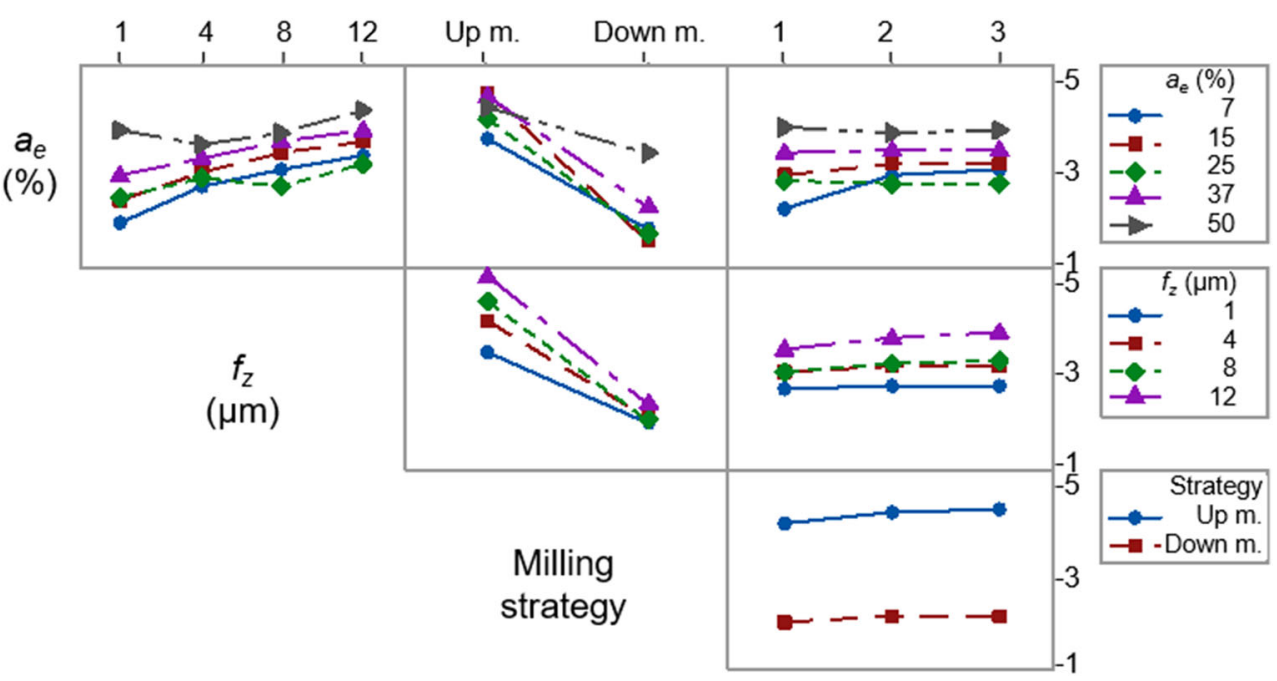

the one hand, this provides better support of the tool in the axial direction. On the other hand, this results in a larger area, which can contribute to better damping. All of these yield improved micro-milling conditions. Similar phenomena were observed in several cases: for example, when $a_{e}=37 \%$ in the case of both strategies and when $a_{e}=50 \%$ in the case of up milling (Fig. 17a).

An analysis of the results of the experiments found that, at small radial depth of cut values, down milling is less favourable regarding vibration amplitudes, but the situation changes with an increase of $a_{e}$. In the case of milling with a width of half diameter of the tool, a slightly decreasing trend can be observed in vibrations coupled with an increase in feed per tooth. This indicates that smaller vibrations contribute to improved chip removal conditions (Fig. 17).

Based on a statistical evaluation, it can be stated that feed per tooth, radial depth of cut, and consecutive infeeds have a significant influence on output parameters. However, the null hypothesis concerning the milling strategy cannot be rejected. The curve belonging to $a_{e}$ does not show a monotone trend, it has a minimum value at $a_{e}=15 \%$, and it has a maximum value at $a_{e}=37 \%$. Furthermore, it is clearly seen in the diagram that consecutive infeeds result in smaller vibrations. The reason for this can be that in the case of the $2^{\text {nd }}$ and $3^{\text {rd }}$ infeeds, the contact zone between the workpiece and the tool face is larger, which ensures better support of the tool in the axial direction and higher process damping. Referent ANOVA results are shown in Fig. 18 and Table 4.

The interactions of the parameters are basically insignificant. The only exception is the interaction between $a_{e}$ and milling strategy $(F$ value $=38.29, P$ value $=0.000)$.

\section{Relation between productivity and cutting force, and vibrations}

Economic aspects, such as productivity, should be taken into consideration when determining optimal cutting parameters. The diagrams in Fig. 19 show the influence of feed per tooth and radial depth of cut on cutting forces, axial forces, and vibrations. The diagrams also display productivity curves, which correspond to the given cutting parameter combination.
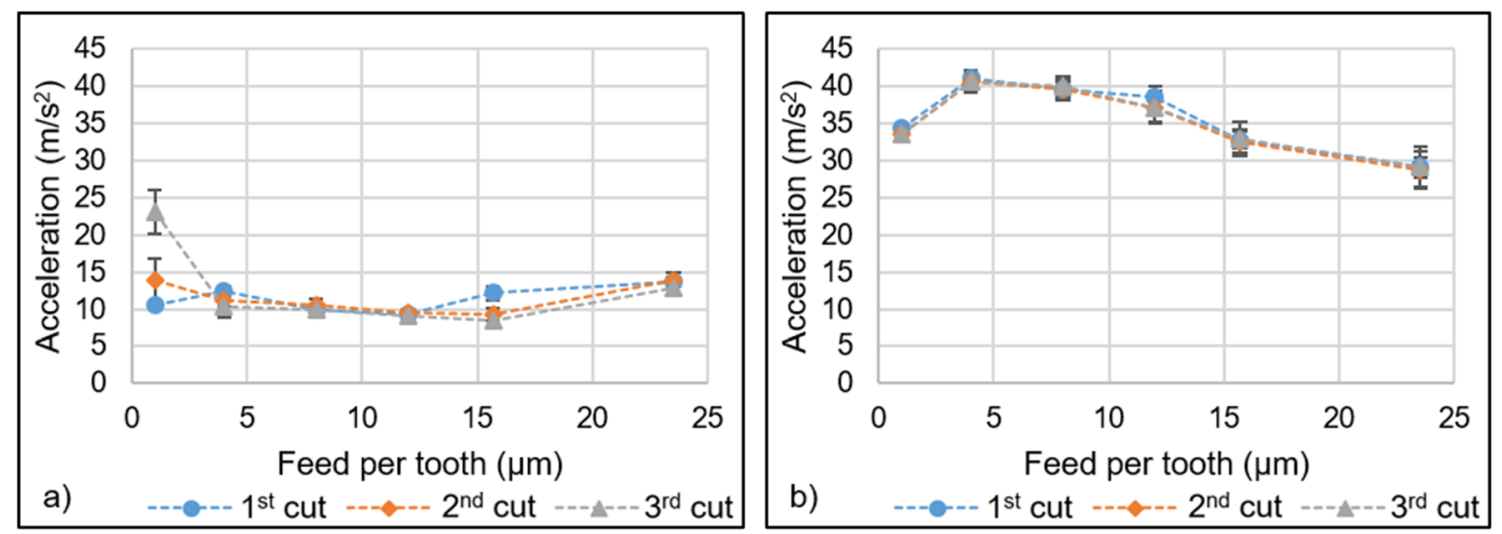

Fig. 15 Vibration as a function of feed per tooth values when $a_{e}=7 \%$ in the case of $\mathbf{a}$ up milling and $\mathbf{b}$ down milling 

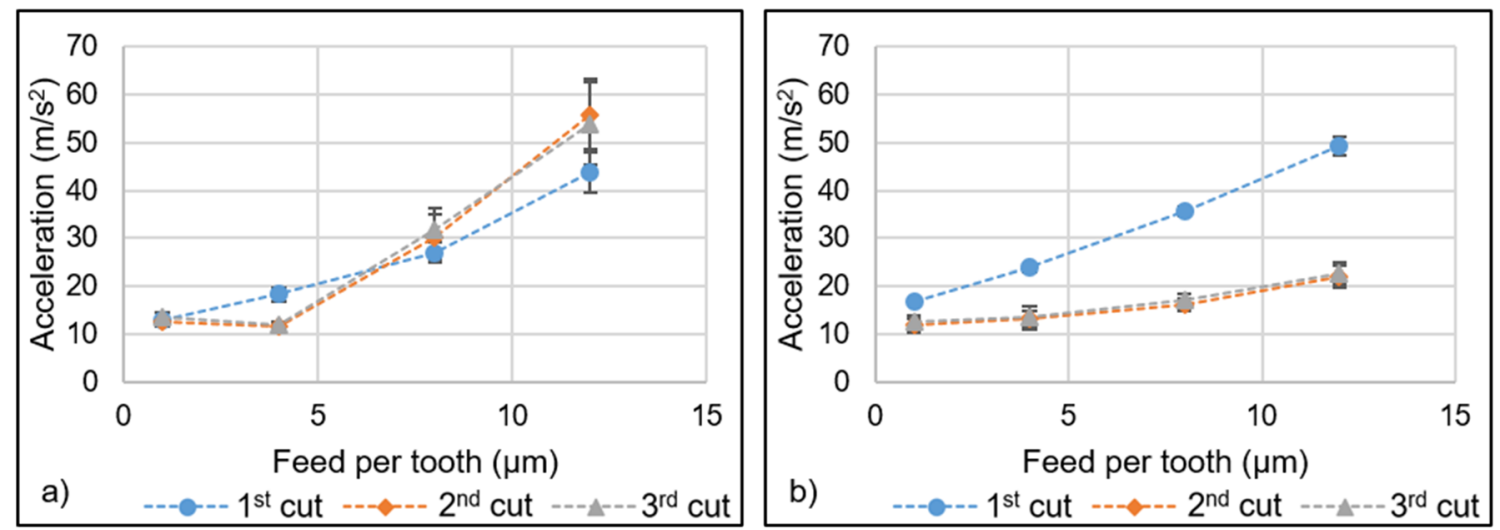

Fig. 16 Vibration as a function of feed per tooth values when $a_{e}=25 \%$ in the case of $\mathbf{a}$ up milling and $\mathbf{b}$ down milling
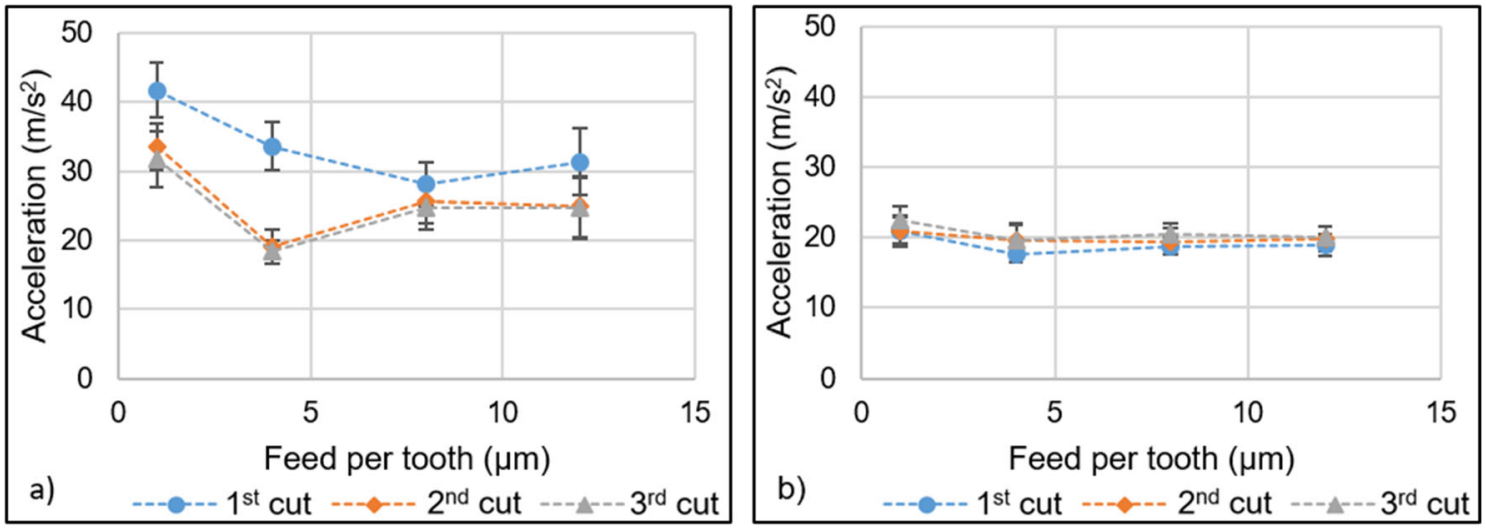

Fig. 17 Vibration as a function of feed per tooth values when $a_{e}=50 \%$ in the case of $\mathbf{a}$ up milling and $\mathbf{b}$ down milling

The given productivity can be achieved through the use of different parameter combinations; therefore, the use of this type of diagram seems expedient for the related analysis and the representation of pertaining data. At the same time, different settings result in different behaviours in terms of the cutting process as far as forces, vibrations, and tool deformations are concerned. The diagrams below were constructed on the

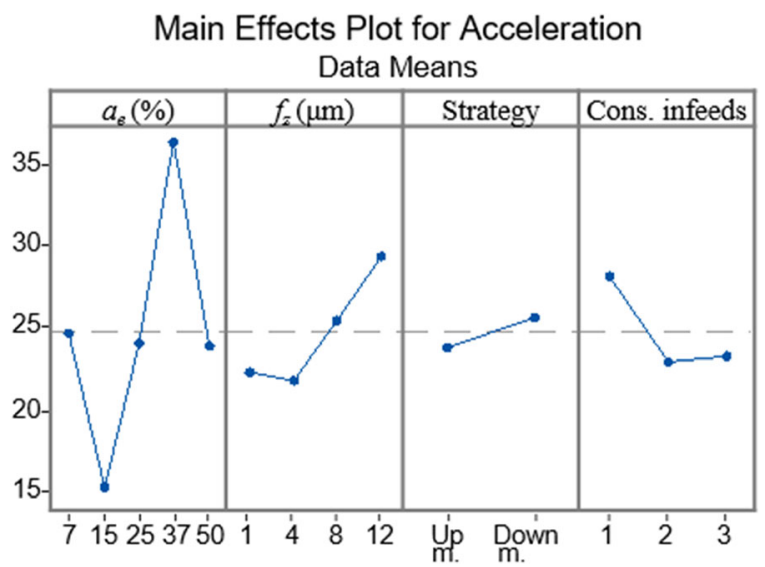

Fig. 18 Main effect plots for acceleration basis of the mean of the results of the three consecutive infeeds.

In the case of down milling, cutting force values were low in a greater area (shown in the diagram) than in the case of up milling. During down milling, increasing the radial depth of cut is recommended in order to increase productivity, since this causes a less marked increase in cutting force. In the case of up milling, it is advisable to increase feed per tooth in terms of the cutting force. Cutting force values increased parallel with the increase of investigated cutting parameters. In contrast, maximum and minimum areas appeared in the case of axial forces and vibrations.

In the case of down milling, $F_{z}$ forces are smaller in a greater area than in the case of up milling. The change in $F_{z}$ forces is different with respect to cutting parameters. In the case of down milling, it is advisable to increase feed per tooth, while in the case of up milling, an increase in the radial depth of cut is proposed.

The minimum value of the $F_{z}$ component belongs to the smallest parameter value setting in the case of up milling. The maximum values were found at the parameter combination of $a_{e}=15 \%$ and $f_{z}=15.68 \mu \mathrm{m}$ and $a_{e}=37 \%$ and $f_{z}=12 \mu \mathrm{m}$, 
Table 4 Results of ANOVA in the case of acceleration

\begin{tabular}{lrll}
\hline Factors & Main effect & $F$ value & $P$ value \\
\hline$a_{e}$ & $21.15\left(\mathrm{~m} / \mathrm{s}^{2}\right)$ & 8.75 & 0.004 \\
$f_{z}$ & $7.63\left(\mathrm{~m} / \mathrm{s}^{2}\right)$ & 9.01 & 0.003 \\
Consecutive infeeds & $5.30\left(\mathrm{~m} / \mathrm{s}^{2}\right)$ & 5.33 & 0.023 \\
Milling strategy & $1.82\left(\mathrm{~m} / \mathrm{s}^{2}\right)$ & 0.04 & 0.849 \\
\hline
\end{tabular}

respectively. In contrast, in the case of down milling, a minimum point was found when $a_{e}=15 \%$ and $f_{z}=4 \mu \mathrm{m}$.

In the case of up milling, vibration values are low in a larger area (Fig. 19f). The maximum value was found when $a_{e}=$ $37 \%$ and $f_{z}=8 \mu \mathrm{m}$, while at $a_{e}=25 \%$, vibration amplitudes were low in the case of all feed per tooth values. In the case of down milling, the minimum value was found at the parameter combination of $a_{e}=15 \%$ and $f_{z}=4 \mu \mathrm{m}$, and the maximum value was found at $a_{e}=37 \%$ and $f_{z}=12$.
In the scope of our research, one of the main aims was to determine an optimal cutting parameter combination that exhibits the following criteria: maximised productivity as well as minimised cutting forces, axial forces, and vibrations. A Minitab-17 was used to determine optimal cutting parameters. In the objective function, different characteristics were taken into account with equal weight. The results are shown in Fig. 20.

In the range of examined cutting parameters, the optimal parameter combination corresponding to the objective function is $a_{e}=34.80 \%, f_{z}=8.28 \mu \mathrm{m}$, and the down milling strategy.

\section{Summary}

Dynamic milling could be applied in macro sizes successfully. Such milling has many advantages including higher
Fig. 19 Relationship between machining parameters and productivity

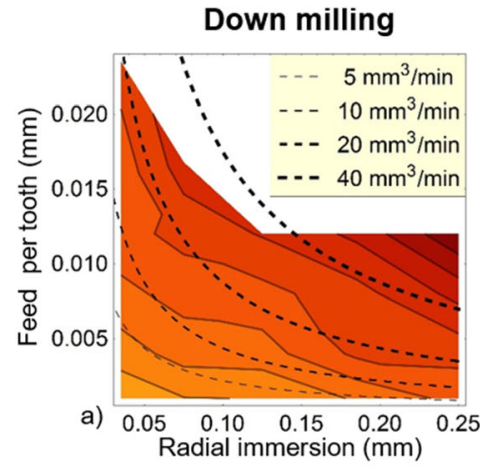

$F_{c}(\mathrm{~N})$
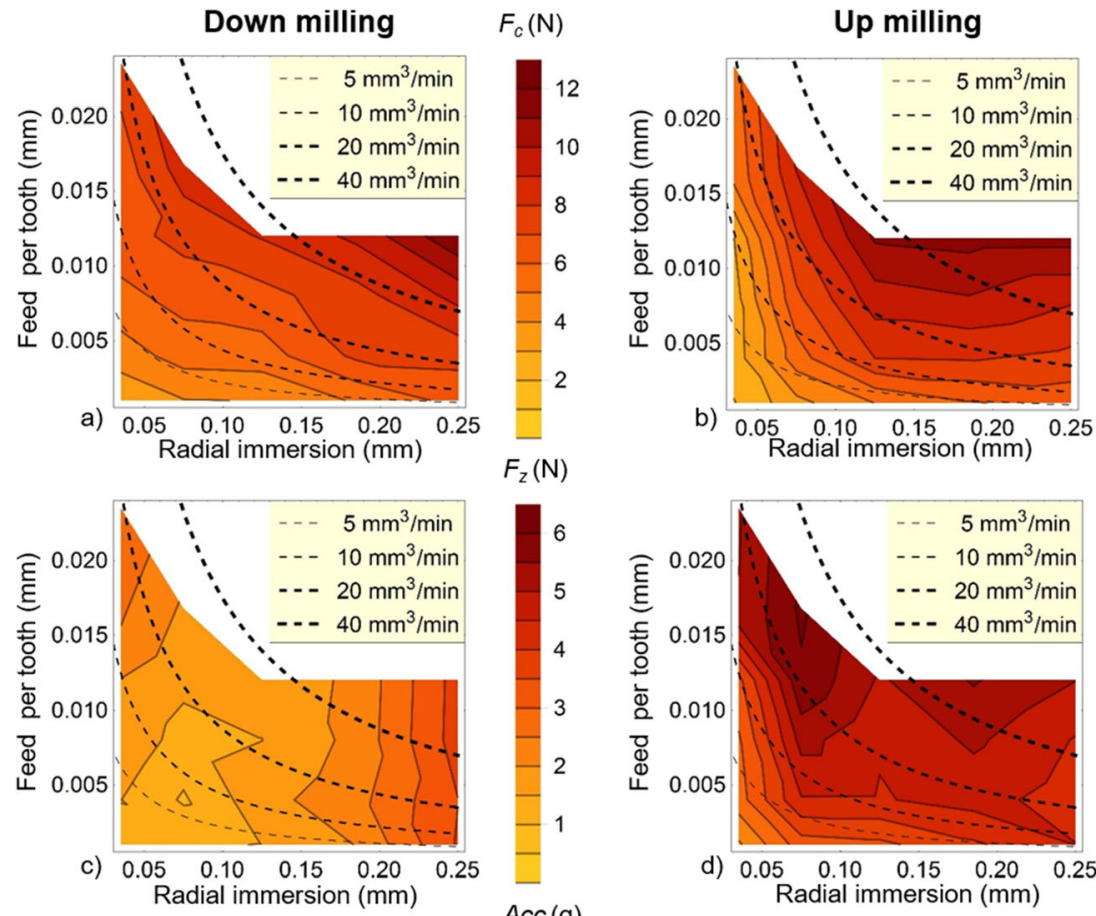

$F_{Z}(\mathrm{~N})$
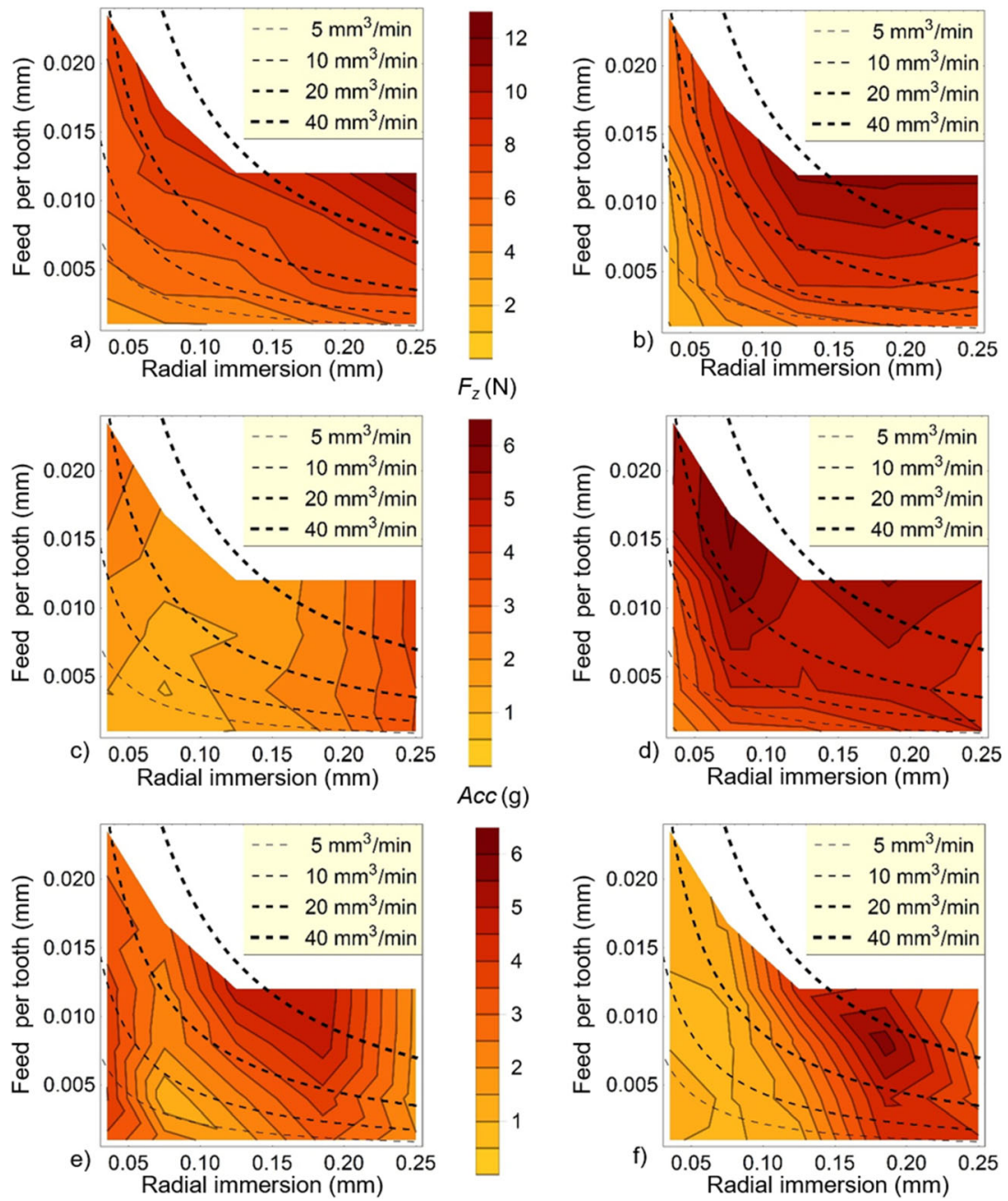


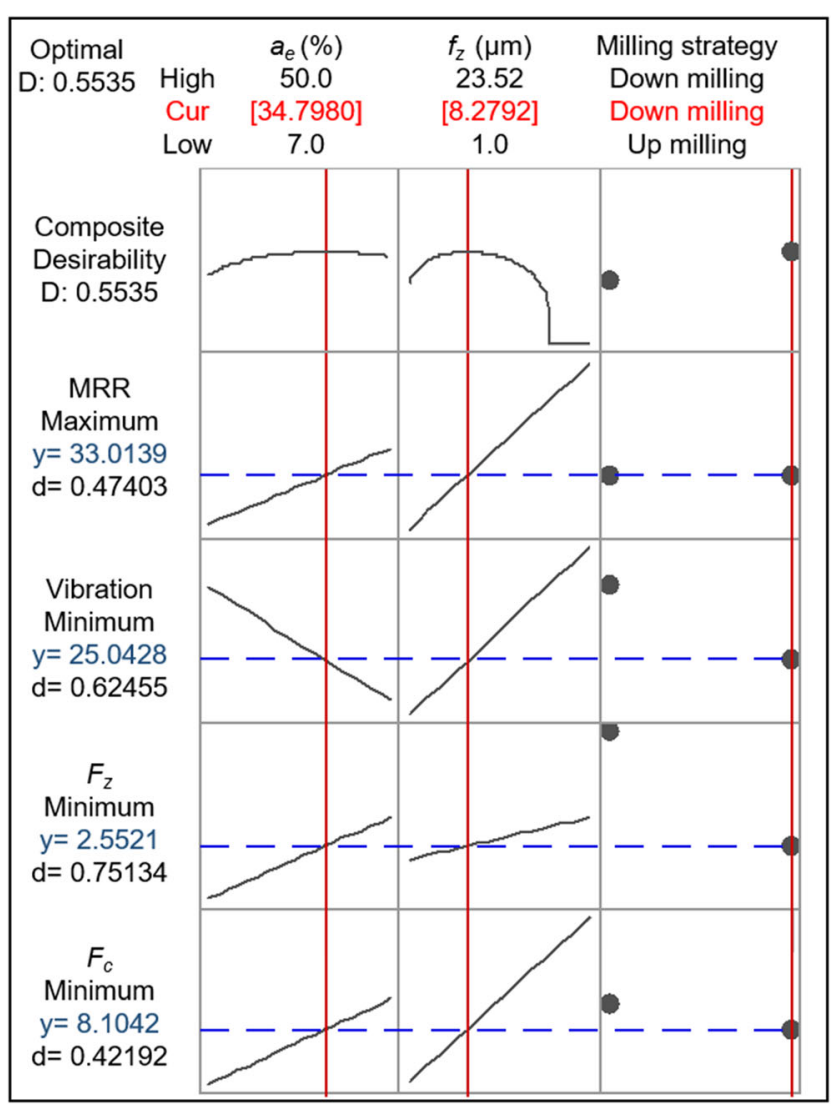

Fig. 20 Result of optimisation (Minitab)

productivity and better thermal conditions. In the case of dynamic milling, wear distributes along the cutting edgecorresponding to the depth of cut-and wear is not concentrated exclusively on the end of the tool. Therefore, it is appropriate to examine dynamic milling in micro sizes. At the same time, it is questionable whether this milling process is actually applicable in view of its size reduction-induced special features (such as relatively large tool deformation, relatively large run-out of the tool, and the problem of minimum chip thickness).

Based on the experiments, the following results can be listed:

- Based on the investigation of dynamic micro-milling, it is stated that the strategy could also be successfully applied in micro sizes.

- Cutting force values increased at consecutive infeeds in the case of small $a_{e}$ values up to $25 \%$ radial depth of cut in the case of up milling. There were no significant differences above $a_{e}=25 \%$ or in the case of down milling. This phenomenon may be caused by relatively large tool deformation induced by minimum chip thickness. Therefore, it is proposed that at least an $a_{e}=25 \%$ radial depth of cut value should be applied.
- $\quad F_{z}$ forces, except for $a_{e}=7 \%$ in the case of up milling, do not show significant differences at consecutive infeeds.

- In the case of down milling, forces were generally smaller than in the case of up milling; therefore, the down milling strategy is recommended.

- At small radial depth of cut values, where the contact angle is small, a significant increase in feed per tooth results in better cutting conditions. A very high feed per tooth value (up to $f_{z}=23.52 \mu \mathrm{m}$ ) may also be required for an effective chip removal process.

- Based on the ANOVA results, all of the four examined factors have a statistically significant effect on $F_{c}$. In the case of $F_{z}$, only the milling strategy, $a_{e}$, and $f_{z}$ influenced the results significantly; and in the case of vibrations, only $a_{e}, f_{z}$ and consecutive infeeds produced the same impact.

- The same chip cross-section or the same productivity can be achieved through the use of several parameter combinations, but their choice is crucial as different parameter combinations result in different cutting circumstances. Taking into consideration forces, vibrations, and productivity, the optimal parameter combination is the following: $a_{e}=34.80 \%, f_{z}=8.28 \mu \mathrm{m}$, and the down milling strategy.

Acknowledgements The authors are grateful for Fraisa Hungary and Böhler Hungary's support. We specifically thank our colleague, Dr. Péter Zentay, for his expert advice in the scope of this research. Open access funding provided by Budapest University of Technology and Economics (BME). The authors gratefully acknowledge support by the Hungarian National Research, Development and Innovation Office through research project No. K 132430 (Transient deformation, thermal, and tribological processes in the case of fine machining of hard metal surfaces). The research reported in this paper has also been supported by the Hungarian National Research, Development and Innovation Fund under program No. TUDFO/51757/2019-ITM (Thematic Excellence Program).

Open Access This article is licensed under a Creative Commons Attribution 4.0 International License, which permits use, sharing, adaptation, distribution and reproduction in any medium or format, as long as you give appropriate credit to the original author(s) and the source, provide a link to the Creative Commons licence, and indicate if changes were made. The images or other third party material in this article are included in the article's Creative Commons licence, unless indicated otherwise in a credit line to the material. If material is not included in the article's Creative Commons licence and your intended use is not permitted by statutory regulation or exceeds the permitted use, you will need to obtain permission directly from the copyright holder. To view a copy of this licence, visit http://creativecommons.org/licenses/by/4.0/.

\section{References}

1. Mittal RK, Kulkarni SS, Singh RK (2017) Effect of lubrication on machining response and dynamic instability in high-speed micromilling of Ti-6Al-4 V. J Manuf Process 28:413-421. https:// doi.org/10.1016/j.jmapro.2017.04.007

2. Beruvides G, Castaño F, Quiza R, Haber RE (2016) Surface roughness modeling and optimization of tungsten-copper alloys in 
micro-milling processes. Measurement 86:246-252. https://oi.org/ 10.1016/j.measurement.2016.03.002

3. Geier N, Davim JP, Szalay T (Oct. 2019) Advanced cutting tools and technologies for drilling carbon fibre reinforced polymer (CFRP) composites: a review. Compos A: Appl Sci Manuf 125: 105552. https://doi.org/10.1016/j.compositesa.2019.105552

4. Cheng K, Huo D (2013) Micro cutting: fundamentals and applications. John Wiley \& Sons, Chichester

5. Câmara MA, Rubio JCC, Abrão AM, Davim JP (2012) 'State of the art on micromilling of materials, a review. J Mater Sci Technol 28(8):673-685. https://doi.org/10.1016/S1005-0302(12)60115-7

6. Balázs BZ, Szalay T, Takács M (2017) Investigation of micro milled surface characteristics. Proc Int Conf Innov Technol:161164

7. Jin X, Altintas Y (Mar. 2012) Prediction of micro-milling forces with finite element method. J Mater Process Technol 212(3):542_ 552. https://doi.org/10.1016/j.jmatprotec.2011.05.020

8. Kumar P, Bajpai V, Singh R (2017) Burr height prediction of Ti6A14V in high speed micro-milling by mathematical modeling. Manuf Lett. https://doi.org/10.1016/j.mfglet.2016.10.001

9. Gao S, Pang S, Jiao L, Yan P, Luo Z, Yi J, Wang X (2017) Research on specific cutting energy and parameter optimization in micro-milling of heat-resistant stainless steel. Int J Adv Manuf Technol 89(1-4):191-205. https://doi.org/10.1007/s00170-0169062-x

10. Bissacco G, Hansen HN, De Chiffre L (2005) Micromilling of hardened tool steel for mould making applications. J Mater Process Technol 167(2-3):201-207. https://doi.org/10.1016/j. jmatprotec.2005.05.029

11. de Oliveira FB, Rodrigues AR, Coelho RT, de Souza AF (2015) Size effect and minimum chip thickness in micromilling. Int J Mach Tools Manuf 89:39-54. https://doi.org/10.1016/j.ijmachtools.2014. 11.001

12. Ramos AC, Autenrieth H, Strauß T, Deuchert M, Hoffmeister J, Schulze V (2012) Characterization of the transition from ploughing to cutting in micro machining and evaluation of the minimum thickness of cut. J Mater Process Technol 212(3):594-600. https://doi. org/10.1016/j.jmatprotec.2011.07.007

13. Kang I-S, Kim J-S, Seo Y-W (2010) Investigation of cutting force behaviour considering the effect of cutting edge radius in the microscale milling of AISI 1045 steel. Proc Inst Mech Eng B J Eng Manuf. https://doi.org/10.1243/09544054JEM1762

14. Liu X, DeVor RE, Kapoor SG (2005) An analytical model for the prediction of minimum chip thickness in micromachining. J Manuf Sci Eng 128(2):474-481. https://doi.org/10.1115/1.2162905

15. Lai X, Li H, Li C, Lin Z, Ni J (2008) Modelling and analysis of micro scale milling considering size effect, micro cutter edge radius and minimum chip thickness. Int J Mach Tools Manuf 48(1):1-14. https://doi.org/10.1016/j.ijmachtools.2007.08.011

16. Malekian M, Mostofa MG, Park SS, Jun MBG (Mar. 2012) Modeling of minimum uncut chip thickness in micro machining of aluminum. J Mater Process Technol 212(3):553-559. https://doi. org/10.1016/j.jmatprotec.2011.05.022

17. Son SM, Lim HS, Ahn JH (2005) Effects of the friction coefficient on the minimum cutting thickness in micro cutting. Int $J$ Mach Tools Manuf 45(4):529-535. https://doi.org/10.1016/j. ijmachtools.2004.09.001

18. Aramcharoen A, Mativenga PT (2009) Size effect and tool geometry in micromilling of tool steel. Precis Eng 33(4):402-407. https:// doi.org/10.1016/j.precisioneng.2008.11.002

19. Mian AJ, Driver N, Mativenga PT (2011) Identification of factors that dominate size effect in micro-machining. Int $\mathrm{J}$ Mach Tools Manuf 51(5):383-394. https://doi.org/10.1016/j.ijmachtools.2011. 01.004

20. Biró I, Szalay T (2017) Extension of empirical specific cutting force model for the process of fine chip-removing milling. Int $\mathrm{J}$ Adv
Manuf Technol 88(9-12):2735-2743. https://doi.org/10.1007/ s00170-016-8957-x

21. Zhou L, Peng F, Yan R, Dong Q, Yang C (2015) Prediction and experimental validation of micro end-milling forces with finite element method. Intell Robot Appl:664-675. https://doi.org/10.1007/ 978-3-319-22876-1_58

22. Wang F, Cheng X, Liu Y, Yang X, Meng F (2017) Micromilling simulation for the hard-to-cut material. Proc Eng 174:693-699. https://doi.org/10.1016/j.proeng.2017.01.209

23. Sun Q, Cheng X, Liu Y, Yang X, Li Y (2017) Modeling and simulation for micromilling mechanisms. Proc Eng 174:760-766. https://doi.org/10.1016/j.proeng.2017.01.219

24. Kuram E, Ozcelik B (2016) Effects of tool paths and machining parameters on the performance in micro-milling of Ti6Al4V titanium with high-speed spindle attachment. Int J Adv Manuf Technol 84(1-4):691-703. https://doi.org/10.1007/s00170015-7741-7

25. Oliaei SNB, Karpat Y (2014) Experimental investigations on micro milling of Stavax stainless steel. Proc CIRP 14:377-382. https:// doi.org/10.1016/j.procir.2014.03.006

26. Dimov S, Pham DT, Ivanov A, Popov K, Fansen K (2004) Micromilling strategies: optimization issues. Proc IMechE 218(7): 731-736. https://doi.org/10.1177/095440540421800706

27. Balázs BZ, Takács M (2020) Experimental investigation and optimisation of the micro milling process of hardened hot-work tool steel. Int J Adv Manuf Technol. https://doi.org/10.1007/s00170020-04991-x

28. Takács M (2006) Sokkristályos ötvözetek mikroforgácsolása keményfém szármaróval. Budapest

29. Takács M, Verő B (2007) Actual feed rate per tooth at micro milling. Mater Sci Forum 537-538:695-700. https://doi.org/10.4028/ www.scientific.net/MSF.537-538.695

30. Wojciechowski S, Matuszak M, Powałka B, Madajewski M, Maruda RW, Królczyk GM (2019) Prediction of cutting forces during micro end milling considering chip thickness accumulation. Int J Mach Tools Manuf 147:103466. https://doi.org/10.1016/j. ijmachtools.2019.103466

31. Davies MA, Pratt JR, Dutterer BS, Burns TJ (2000) The stability of low radial immersion milling. CIRP Ann 49(1):37-40. https://doi. org/10.1016/S0007-8506(07)62891-1

32. Jacso A, Szalay T (2018) Analysing and optimizing 2.5D circular pocket machining strategies. Lect Notes Mech Eng 201519:355364. https://doi.org/10.1007/978-3-319-68619-6_34

33. R. Yan, H. Li, F. Peng, X. Tang, J. Xu, and H. Zeng. Stability prediction and step optimization of Trochoidal milling. J. Manuf. Sci. Eng 139(9):091006-091006-11, 2017, doi: 10.1115/ 1.4036784

34. Huang W, Li X, Wang B, Chen J, Zhou J (2016) An analytical index relating cutting force to axial depth of cut for cylindrical end mills. Int J Mach Tools Manuf 111:63-67. https://doi.org/10. 1016/j.ijmachtools.2016.10.003

35. A. Jacso, T. Szalay, J. C. Jauregui, and J. R. Resendiz. A discrete simulation-based algorithm for the technological investigation of $2.5 \mathrm{D}$ milling operations. Proceedings of the Institution of Mechanical Engineers, Part C: Journal of Mechanical Engineering Science 78-90, 2018, doi: 10.1177/ 0954406218757267.

36. Budak E, Tekeli A (2005) Maximizing chatter free material removal rate in milling through optimal selection of axial and radial depth of cut pairs. CIRP Ann 54(1):353-356. https://doi.org/10.1016/ S0007-8506(07)60121-8

37. Shixiong W, Zhiyang L, Chengyong W, Suyang L, Wei M (Apr. 2018) Tool wear of corner continuous milling in deep machining of hardened steel pocket. Int J Adv Manuf Technol 97:119. https://doi.org/10.1007/s00170-018-1994-x 
38. Uddin MS, Ibaraki S, Matsubara A, Nishida S, Kakino Y (2006) Constant engagement tool path generation to enhance machining accuracy in end milling. JSME Int J Ser C Mech Syst Mach Elem Manuf 49(1):43-49. https://doi.org/10.1299/jsmec.49.43

39. Wang C, Zhang X, Cao H, Chen X, Xiang J (2018) Milling stability prediction and adaptive chatter suppression considering helix angle and bending. Int J Adv Manuf Technol 95(9-12):3665-3677. https://doi.org/10.1007/s00170-017-1389-4

40. Biró I, Szalay T, Geier N (2018) Effect of cutting parameters on section borders of the empirical specific cutting force model for cutting with micro-sized uncut chip thickness. Proc CIRP 77:279282. https://doi.org/10.1016/j.procir.2018.09.015
41. Zhai Z, Lin Z, Fu J (Apr. 2018) HSM toolpath generation with capsule-based region subdivision. Int J Adv Manuf Technol 97:113. https://doi.org/10.1007/s00170-018-2035-5

42. voestalpine BÖHLER Edelstahl GmbH \& Co KG - Hot work tool steels. https://www.bohler-edelstahl.com/en/product-category/hotwork-tool-steels/. Accessed 14 May 2020

43. Takács M, Balázs BZ, Jáuregui JC (2017) Dynamical aspects of micro milling process. Proc Int Conf Innov Technol:181-184

Publisher's note Springer Nature remains neutral with regard to jurisdictional claims in published maps and institutional affiliations. 